Check for updates

Cite this: RSC Adv., 2018, 8, 14454

Received 4th January 2018

Accepted 9th April 2018

DOI: $10.1039 / c 8 \mathrm{ra00082d}$

rsc.li/rsc-advances

\section{Comparative study on the dynamic properties of lightweight porous concrete}

\begin{abstract}
Er-Lei Bai, D *a Jin-Yu Xu, ab Song Lu, (D) ${ }^{a}$ Ke-Xin Lin ${ }^{c}$ and Yi-Ming Zhang ${ }^{d}$
In this paper, two types of lightweight porous concrete material, expanded polystyrene concrete (EPSC) and ceramics-cement based porous material (CCPM) have been prepared on the base of C60 concrete. The dynamic mechanical experiments of lightweight porous concretes have been carried out by $\Phi 100 \mathrm{~mm}$ split Hopkinson pressure bar (SHPB) improved by wave shaping technology. The dynamic properties, including strength properties, deformation properties, impact toughness and energy absorption properties, of lightweight porous concretes have been analyzed comparatively, and its application prospects have been discussed. The results show that the two types of lightweight porous concretes are strain rate sensitive. Dynamic compression strength increases with strain rate; the correlation between the peak strain, ultimate strain of lightweight porous concrete and strain rate can be expressed by quadratic polynomial; under the impact loading, the impact toughness of lightweight porous concretes increases with strain rate, the amount of absorbed energy increases with the average incident energy change rate, moreover, the relation between the impact toughness and strain rate, and that between the amount of absorbed energy and the average incident energy change rate can both be expressed by exponential functions; compared with EPSC, CCPM has better properties in terms of strength, deformation, impact toughness and energy absorption. Those advantages are more obvious with high strain rate. Therefore, CCPM has more vast application prospects in civil defense projects than EPSC.
\end{abstract}

\section{Introduction}

Lightweight porous concrete is a kind of construction material. Owing to the addition of a large number of pores to the concrete, lightweight porous concrete, like autoclaved aerated concrete, ceramsite concrete (ceramsite is a kind of lightweight porous aggregate added into concrete), and expanded polystyrene concrete (EPSC), is light, heat preserving, heat isolating and porous. As a result, it has good prospects for application. Lightweight porous concrete belongs to the category of porous material. With a large number of pores, lightweight porous concrete has compressibility, and compressive stress platform, and its Poisson's ratio is almost zero. Those qualities make lightweight porous material an excellent energy-absorbing material.

Until now, a large number of research studies have been conducted with regard to the mechanical performance of porous material. For instance, Silva and Gibson conducted

${ }^{a}$ Department of Airfield and Building Engineering, Air Force Engineering University, Xi'an 710038, China.E-mail: baierlei647@163.com

${ }^{b}$ College of Mechanics and Civil Architecture, Northwest Polytechnic University, Xi'an 710072, China

${ }^{c}$ Engineering Quality Supervision Station, The Sixth Air Defense Engineering Department, Guangzhou 510052, China

${ }^{d}$ Transport Barracks Section, Ninth Brigade of Air Force Radar, Shijiazhuang 100720, China mechanical experiments on the porous materials and analyzed their deformation properties. According to their research, nonperiodic microstructure could lead to increasing more deformation and decreasing more strength compared with periodic microstructure. ${ }^{1}$ Wang conducted a certain research on the dynamic performance of porous material under impact loading. The results show that porous material could exhibit excellent performance in the resistance of explosive or impact loading. ${ }^{2}$ In view of the advantages in energy absorption, lightweight porous concretes have important application prospects in the civil defense project. EPSC $^{3-5}$ is the most outstanding in performance according to present research situation. Ceramics-cement based porous material (CCPM) is a new kind of composite material, which possesses the double advantages of concrete material and porous material, and can play the superimposed effect of them. So far, the research on the dynamic performance of porous concrete is yet not much. Luo et al. studied the dynamic performance of porous concrete. The results indicated that this material possessed excellent dynamic performance, especially in the deformation performance. ${ }^{6}$ Therefore, as new materials in civil defense project, researches on the contrast of EPSC and CCPM have important application value in guidance of material selection of civil defense engineering. Besides, the related researches are also helpful to promote the development of porous materials. 
In this paper, the expanded polystyrene (EPS) and ceramsite aggregate were used as the lightweight porous aggregate added into the matrix of C60 concrete. On the basis of this matrix, EPSC and CCPM have been prepared. The dynamic mechanical experiments of lightweight porous concretes have been carried out with $\Phi 100 \mathrm{~mm}$ split Hopkinson pressure bar (SHPB) improved by wave shaping technology; the mechanical parameters under different strain rates have been obtained; the dynamic properties of lightweight porous concretes, including strength property, deformation property, impact toughness and energy absorption properties have been analyzed contrastively, and its application prospects have been discussed.

\section{Basic situation of the test}

\subsection{Matrix design}

The raw materials used to prepare C60 ordinary concrete mainly include: cement, fly ash, sand, gravel, superplasticizer, silica fume, and water.

The basic property of each composition is listed as below: $42.5 \mathrm{R}$ ordinary portland cement; grade I fly ash (low calcium); medium sand: fineness modulus is 2.78 , grading qualified, density is $2.63 \mathrm{~g} \mathrm{~cm}^{-3}$, bulk density is $1.50 \mathrm{~kg} \mathrm{~L}^{-1}$, silt content is $1.1 \%$; crushed limestone: particle size is $5-20 \mathrm{~mm}$, density is $2.70 \mathrm{~g} \mathrm{~cm}^{-3}$, bulk density is $1.62 \mathrm{~kg} \mathrm{~L}^{-1}$, silt content is $0.2 \%$; superplasticizer: water reducing rate is $20 \%$; silica fume: average particle size is $0.1-0.15 \mu \mathrm{m}$, specific surface area is $15-$ $27 \mathrm{~m}^{2} \mathrm{~g}^{-1}, \mathrm{SiO}_{2}$ content is $85-95 \%$.

The mixture ratio of 660 ordinary concrete is shown in the Table 1.

\subsection{Preparation of lightweight porous concrete}

EPSC is a sort of composite material which adopt expanded polystyrene (EPS) particles to displace the sand and gravel aggregate under the condition of the same volume, and the volume ratio between sand and stone in the matrix is maintained. In this paper, EPSC with the EPS volume content of 50\% has been prepared.

The mixture ratio of EPSC is shown in Table 2.

The mixing system of EPSC: according to the characteristics of EPS, to improve its adhesion with cement paste and to prevent segregation and layering, after repeated trial mix, the mixing process should be as follows: firstly, mix fly ash, silicon ash, admixture, part of cement and water together to form a mortar with low water-cement ratio (30 s); then add EPS particles ( $30 \mathrm{~s})$, and then add the rest of the water and cement, and mix for $30 \mathrm{~s}$, and finally add sand, stone (120 s), stir into uniform mixture.
Ceramic aggregate includes alumina hollow ball $\left(\mathrm{Al}_{2} \mathrm{O}_{3}>\right.$ $99 \%$ ), compressive strength at normal temperature $>8 \mathrm{MPa}$, four parts of particle size level $(0.2-1.0 \mathrm{~mm}, 1.0-2.0 \mathrm{~mm}, 2.0-3.0$ $\mathrm{mm}, 3.0-5.0 \mathrm{~mm}$ ) are used and ceramsite (packing density is $510 \mathrm{~kg} \mathrm{~m}^{-3}$ ), cylinder pressure strength $\geq 1.5 \mathrm{MPa}$, water absorption $\leq 15 \%$, shape coefficient is "globular shape $\leq 1.6$ " (the ratio of the maximum size of aggregate particles to the minimum size of its middle section). CCPM has been prepared on the base of C60 ordinary concrete, which adopted alumina hollow ball and ceramsite to displace the sand and gravel aggregate completely, and the volume ratio between alumina hollow ball and ceramsite determined according to their particle size distribution. The mixture ratio of CCPM is presented in Table 3.

The mixing system of CCPM: mix superplasticizer and water up previously, and keep it for further use. Considering the characteristics of the alumina hollow balls and ceramsite, the mixing process should be as follows: the mixing process: (1) stir the micro-silica and half amount of the cement for 30 seconds. (2) Add three quarters of the prepared superplasticizer and continue to stir for 30 seconds. (3) Add the ceramsites and stir for another 30 seconds; (4) add the remaining superplasticizer and cement, stir the mixture for another 120 seconds, and the uniform mixture is made. Put the mixture out of the mixer, and manually blend it while sprinkling the alumina hollow balls.

\subsection{Specimen and its basic characteristics}

According to the requirements of the test, fresh concrete is enclosed in the mould. To prevent water loss on the surface, it should be covered with plastic wrap. After 28 days of standard curing $\left(T=20+2{ }^{\circ} \mathrm{C}\right.$, relative humidity $\left.\mathrm{RH}>95 \%\right)$, take the specimens out and the cylindrical specimens used in the dynamic compression tests have been prepared. The cylindrical specimens should be polished to control their width and surface flatness, with geometry size of $\Phi 95 \times 50 \mathrm{~mm}$, as shown in Fig. 1.

The test shows that the quasi-static compressive strength of EPSC is $15.64 \mathrm{MPa}$, and the bulk density is $1494.71 \mathrm{~kg} \mathrm{~m}^{-3}$; the quasi-static compressive strength $\left(f_{\mathrm{c}, \mathrm{s}}\right)$ of CCPM is $18.27 \mathrm{MPa}$, and the bulk density is $1397 \mathrm{~kg} \mathrm{~m}^{-3}$.

\section{Dynamic properties testing technology}

\subsection{SHPB test system}

As is shown in Fig. 2, a 100 mm-diameter $\mathrm{SHPB}^{7-9}$ is used for testing, and this apparatus consists of main body, energy source and measurement systems.

Table 1 The mixture ratio of C60 ordinary concrete

\begin{tabular}{llllll}
\hline $\begin{array}{l}\text { Cement } \\
\left(\mathrm{kg} \mathrm{m}^{-3}\right)\end{array}$ & $\begin{array}{l}\text { Fly ash } \\
\left(\mathrm{kg} \mathrm{m}^{-3}\right)\end{array}$ & $\begin{array}{l}\text { Silicon ash } \\
\left(\mathrm{kg} \mathrm{m}^{-3}\right)\end{array}$ & $\begin{array}{l}\text { Superplasticizer } \\
\left(\mathrm{kg} \mathrm{m}^{-3}\right)\end{array}$ & $\begin{array}{l}\text { Water } \\
\left(\mathrm{kg} \mathrm{m}^{-3}\right)\end{array}$ & $\begin{array}{l}\text { Sand } \\
\left(\mathrm{kg} \mathrm{m}^{-3}\right)\end{array}$ \\
\hline 386 & 213.5 & 29.68 & 5.93 & 184 & 599
\end{tabular}


Table 2 The mixture ratio of EPSC

\begin{tabular}{lllllll}
\hline $\begin{array}{l}\text { Cement } \\
\left(\mathrm{kg} \mathrm{m}^{-3}\right)\end{array}$ & $\begin{array}{l}\text { Fly ash } \\
\left(\mathrm{kg} \mathrm{m}^{-3}\right)\end{array}$ & $\begin{array}{l}\text { Silicon ash } \\
\left(\mathrm{kg} \mathrm{m}^{-3}\right)\end{array}$ & $\begin{array}{l}\text { Superplasticizer } \\
\left(\mathrm{kg} \mathrm{m}^{-3}\right)\end{array}$ & $\begin{array}{l}\text { Water } \\
\left(\mathrm{kg} \mathrm{m}^{-3}\right)\end{array}$ & $\begin{array}{l}\text { Sand } \\
\left(\mathrm{kg} \mathrm{m}^{-3}\right)\end{array}$ & $\begin{array}{l}\text { Gravel } \\
\left(\mathrm{kg} \mathrm{m}^{-3}\right)\end{array}$ \\
\hline 386 & 213.5 & 29.68 & 5.93 & 184 & 122 & 219 \\
$(\mathrm{~L})$
\end{tabular}

The length of the projectile is $500 \mathrm{~mm}$. The diameter of the compression bar is $100 \mathrm{~mm}$. The input bar, transmission bar and absorbing bar are as long as $4.5 \mathrm{~m}, 2.5 \mathrm{~m}$ and $1.8 \mathrm{~m}$ respectively. They share the same standards as they are made 48 CrMoA, their elastic modulus is $210 \mathrm{GPa}$, Poisson's ratio is $0.25-$ 0.3 and density is $7850 \mathrm{~kg} \mathrm{~m}^{-3}$.

The basic principle of SHPB testing is the propagation theory of elastic stress wave on the bar, and the test is based on the two following basic assumptions: (1) plane assumption: in the propagation process, each cross section of the elastic bar always keeps in a plane state. (2) Equal stress assumption: the stress in the specimen is equal everywhere. In the dynamic experiment, the specimens are placed between the input bar and output bar. When the striker bar is pulsed by the high pressure gas from gas tank, it will strike the input bar and form an elastic stress wave. Then, the elastic stress wave will spread through the input bar. When the wave reach at the interface between input bar and specimen, some wave will pass through the interface and go into the specimen, the rest will be reflected into the input bar. When the wave going into specimen reach at the interface between specimen and output bar, some wave will also be reflected into specimen and the rest will spread into the output bar. As a result, the wave in the specimen will be reflected back and forth and finally a state of equilibrium is reached.

\subsection{Data processing method}

Incident pulse $\varepsilon_{\mathrm{i}}$, reflected pulse $\varepsilon_{\mathrm{r}}$ and transmitted pulse $\varepsilon_{\mathrm{t}}$ can be recorded by the strain gauge on the bar. Based on the plane and equal stress assumption and the one-dimensional stress wave theory, the measurement data can be converted into strain rate $\left(\dot{\varepsilon}_{\mathrm{s}}(t)\right)$, stress $\left(\sigma_{\mathrm{s}}(t)\right)$ and strain $\left(\varepsilon_{\mathrm{s}}(t)\right)$, which can be expressed respectively as:

$$
\left.\begin{array}{c}
\dot{\varepsilon}_{\mathrm{s}}(t)=\frac{\left(\varepsilon_{\mathrm{i}}-\varepsilon_{\mathrm{r}}-\varepsilon_{\mathrm{t}}\right) c}{l_{\mathrm{s}}} \\
\sigma_{\mathrm{s}}(t)=\frac{E\left(\varepsilon_{\mathrm{i}}+\varepsilon_{\mathrm{r}}+\varepsilon_{\mathrm{t}}\right) A}{2 A_{\mathrm{s}}} \\
\varepsilon_{\mathrm{s}}(t)=\frac{c}{l_{\mathrm{s}}} \int_{0}^{t}\left(\varepsilon_{\mathrm{i}}-\varepsilon_{\mathrm{r}}-\varepsilon_{\mathrm{t}}\right) \mathrm{d} \tau
\end{array}\right\}
$$

where $E$ is the Young's modulus of bars, $c$ is the wave velocity in bars; $A$ and $A_{\mathrm{s}}$ are cross-sectional areas of bars and the specimen respectively; $l_{\mathrm{s}}$ is the original length of the specimen.

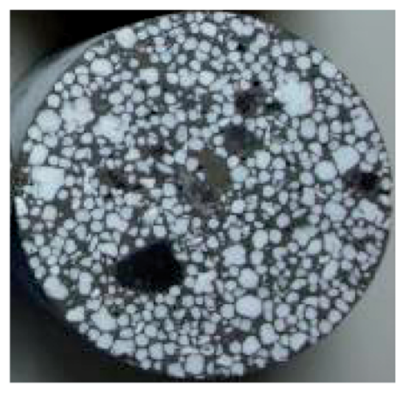

(a)

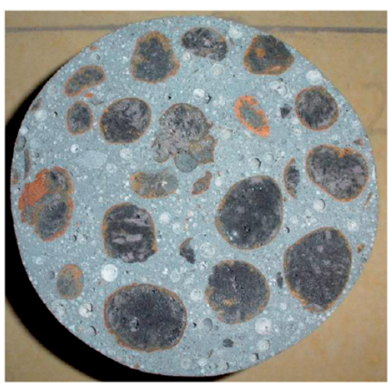

(b)
Fig. 1 Cylindrical specimens. (a) EPSC, (b) CCPM.

\subsection{The key technology}

In order to guarantee the validity of the test, $\mathrm{H} 62$ brass pulse shapers of different geometries i.e. $1 \mathrm{~mm}$ thickness and $20 \mathrm{~mm}$, $22 \mathrm{~mm}, 25 \mathrm{~mm}, 27 \mathrm{~mm}$ and $30 \mathrm{~mm}$ diameter, as shown in Fig. 3, are designed to improve the SHPB test system.

Numerous studies have shown that wave shaping technology ${ }^{10-13}$ can achieve the following objectives: smooth waveform, eliminate the highly frequent oscillation of stress wave, reduce the wave dispersion in long distance transmission. As waveform grows wider, the rising edge of incident wave is extended, and the specimens have enough time to achieve uniform stress. As a result, constant strain rate loading can be realized.

\section{Dynamic properties}

\subsection{Stress strain curve}

Fig. 4 shows dynamic compression stress-strain curve of lightweight porous concretes.

According to the Fig. 4, there are some similarities and differences between the stress strain curves of the two types of lightweight porous concretes: first of all, strain rate has an influence on the stress strain curve, and the stress strain curve changes with strain rate, but comparatively, strain rate has higher effect on the stress strain curve of CCPM than that of EPSC. That means in terms of stress strain curve, strain rate sensitivity of CCPM is stronger. Secondly, platform

Table 3 The mixture ratio of CCPM

\begin{tabular}{llllll}
\hline $\begin{array}{l}\text { Cement } \\
\left(\mathrm{kg} \mathrm{m}^{-3}\right)\end{array}$ & $\begin{array}{l}\text { Fly ash } \\
\left(\mathrm{kg} \mathrm{m}^{-3}\right)\end{array}$ & $\begin{array}{l}\text { Silicon ash } \\
\left(\mathrm{kg} \mathrm{m}^{-3}\right)\end{array}$ & $\begin{array}{l}\text { Superplasticizer } \\
\left(\mathrm{kg} \mathrm{m}^{-3}\right)\end{array}$ & $\begin{array}{l}\text { Water } \\
\left(\mathrm{kg} \mathrm{m}^{-3}\right)\end{array}$ & $\begin{array}{l}\text { Ceramsite } \\
\left(\mathrm{kg} \mathrm{m}^{-3}\right)\end{array}$ \\
\hline 386 & 213.5 & 29.68 & 5.93 & 184 & 352
\end{tabular}




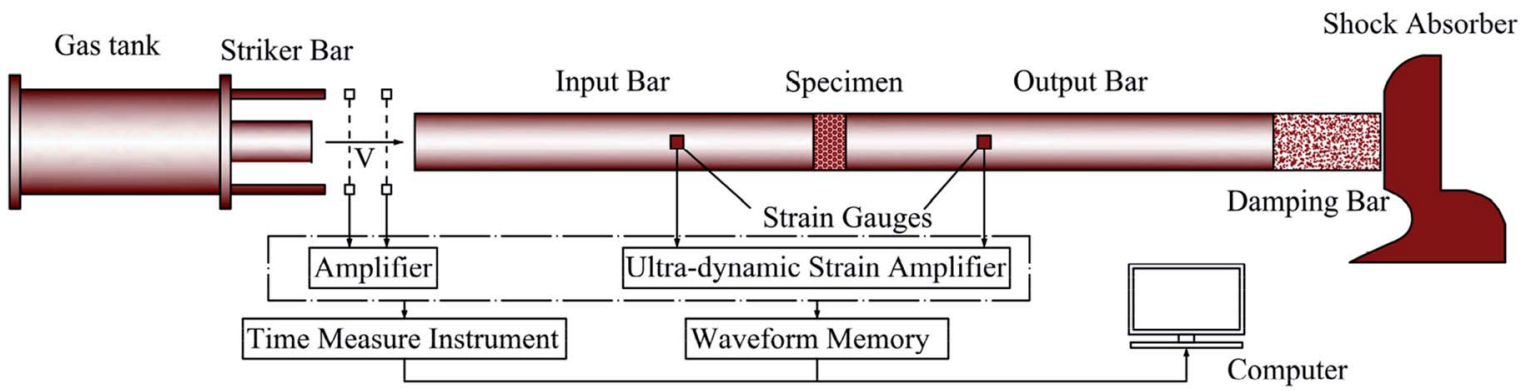

Fig. 2100 mm-diameter SHPB apparatus.

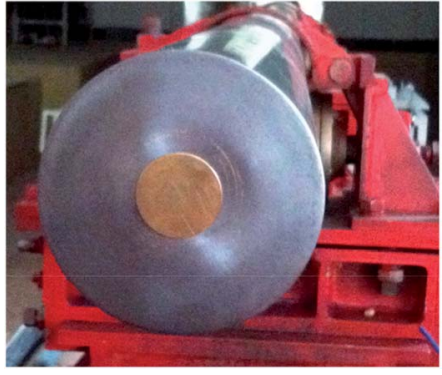

Fig. 3 Pulse shaper used in SHPB apparatus.

phenomenon appears in the stress strain curve, that's to say, as strain increases, the stress is not changed. The difference is that the platform phenomenon embodied in the stress strain curve of EPSC occurs only after the peak stress, but the platform phenomenon embodied in the stress strain curve of CCPM occurs both before and after peak stress.

\subsection{Strength properties}

The dynamic compression strength $f_{\mathrm{c}, \mathrm{d}}$ is defined as peak stress in the dynamic compression test. $f_{\mathrm{c}, \mathrm{d}}$ is one of the major indicators reflecting dynamic strength of the material. Fig. 5 shows the $f_{\mathrm{c}, \mathrm{d}}$ different strain rates.

As shown in Fig. $5, f_{\mathrm{c}, \mathrm{d}}$ of lightweight porous concrete increases with strain rate. The amplitude of $f_{\mathrm{c}, \mathrm{d}}$ increases 1.2 times more than $f_{c, s}$ does. This difference is more prominent when it comes to CCPM. When $\bar{\varepsilon}=114.75 \mathrm{~s}^{-1}$, the difference between $f_{\mathrm{c}, \mathrm{d}}$ and $f_{\mathrm{c}, \mathrm{s}}$ is 3.048 times and when $\overline{\dot{\varepsilon}}=126.43 \mathrm{~s}^{-1}$, it is 3.174 times. Thus it can be seen that, the two types of lightweight porous concrete are both strain rate sensitive. This point is consistent with the conclusions got by the scholars ${ }^{14-17}$ studying the dynamic mechanical performance of ordinary cement based composite material. It shows that cement based composite materials have some common characteristic, and it also testifies the accuracy of the test. The phenomenon that strength increases with strain rate can be called strain rate hardening effect, which is an integrated embodiment of Stefan effect $^{18}$ and inertia effect. ${ }^{19}$

By comparison, the strength sensitivity of CCPM is stronger than that of EPSC. This difference is particularly prominent in low strain rate. When $\overline{\dot{\varepsilon}}=37.69 \mathrm{~s}^{-1}, f_{\mathrm{c}, \mathrm{d}}$ of CCPM is 2.41 times $f_{\mathrm{c}, \mathrm{s}}$, while when $\overline{\dot{\varepsilon}}=55.58 \mathrm{~s}^{-1}, f_{\mathrm{c}, \mathrm{d}}$ of EPSC is only 1.288 times $f_{\mathrm{c}, \mathrm{s}}$. Thus it can be seen, when applied to projects withstanding impact and explosion loading, CCPM has obvious advantages in strength. The more the impact intensity is, the higher the strength.

\subsection{Deformation properties}

Peak strain and ultimate strain are important indexes of deformation characteristics. Peak strain in the dynamic compression test is identified as $\varepsilon_{\mathrm{p}, \mathrm{d}}$ and ultimate strain is

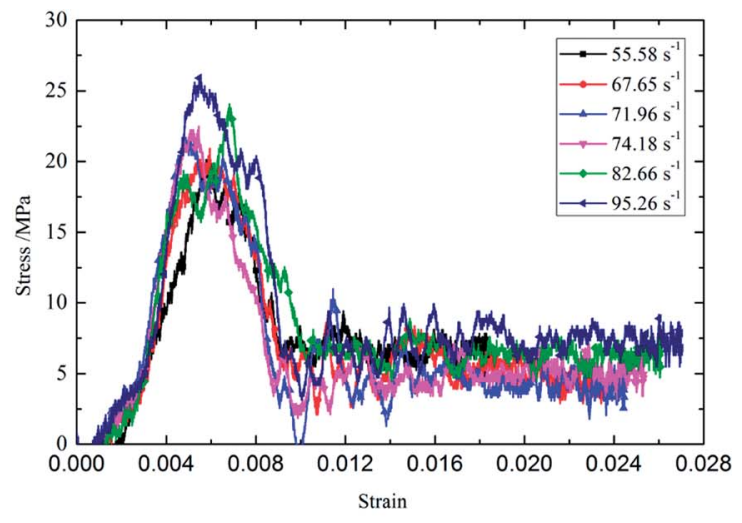

(a)

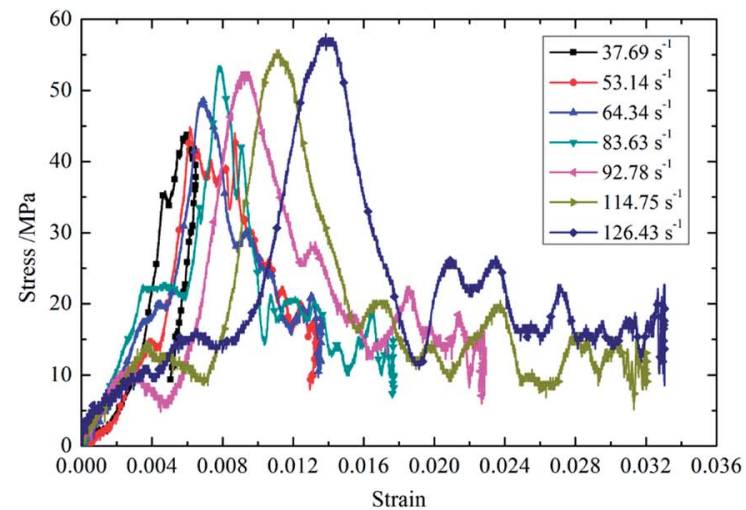

(b)

Fig. 4 Stress-strain curves. (a) EPSC, (b) CCPM. 


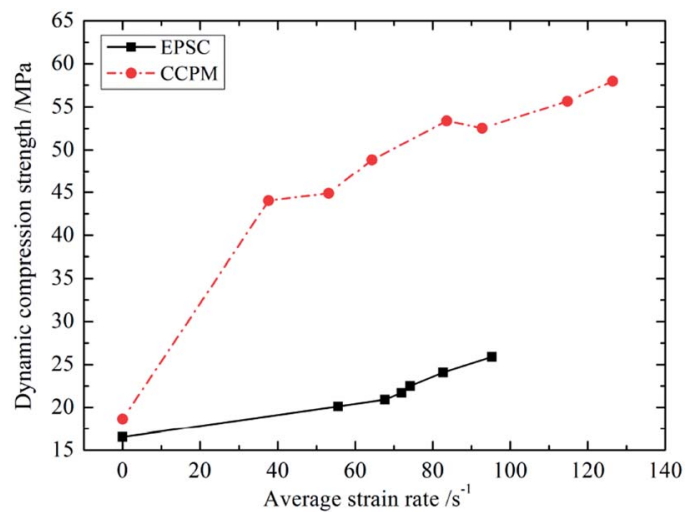

Fig. 5 The relationship between $f_{\mathrm{c}, \mathrm{d}}$ and $\overline{\dot{\varepsilon}}$.

identified as $\varepsilon_{\mathrm{L}, \mathrm{d}}$. Fig. 6 shows the relationship between $\varepsilon_{\mathrm{p}, \mathrm{d}}$ and average strain rate.

The figure shows that $\varepsilon_{\mathrm{p}, \mathrm{d}}$ of lightweight porous concretes changes with strain rate. The $\varepsilon_{\mathrm{p}, \mathrm{d}}$ of CCPM increases with strain rate, while the $\varepsilon_{\mathrm{p}, \mathrm{d}}$ of EPSC decreases with the increase of strain rate. Through analysis, the correlation between $\varepsilon_{\mathrm{p}, \mathrm{d}}$ and $\overline{\dot{\varepsilon}}$ can be expressed by a quadratic polynomial, as shown in formula (2):

$$
\left\{\begin{array}{l}
\varepsilon_{\mathrm{p}, \mathrm{d}(\mathrm{EPSC})}=-3.72 \times 10^{-9}(\overline{\dot{\varepsilon}})^{2}-1.48 \times 10^{-5} \overline{\dot{\varepsilon}}+0.00664 \\
\varepsilon_{\mathrm{p}, \mathrm{d}(\mathrm{CCPM})}=1.0142 \times 10^{-6}(\overline{\dot{\varepsilon}})^{2}-8.21 \times 10^{-5} \overline{\dot{\varepsilon}}+0.00769
\end{array}\right.
$$

The formula above is similar to the experience formulas obtained by Tedesco ${ }^{20}$ and Dilger. ${ }^{21}$

By comparison, it shows that when strain rate is low, the peak strains of EPSC and CCPM appear to be a little different. But as strain rate increases, the difference between the peak strains of the two types of lightweight porous concrete grows bigger and bigger. When $\overline{\dot{\varepsilon}} \geq 100 \mathrm{~s}^{-1}, \varepsilon_{\mathrm{p}, \mathrm{d}}$ of CCPM is more than 1.5 times that of EPSC. The reasons can be listed as follows. When the strain rate is low, the deformation degrees of the porous aggregates added in EPSC and CCPM are similar as the stress reach at the peak. As the strain rate increases, the

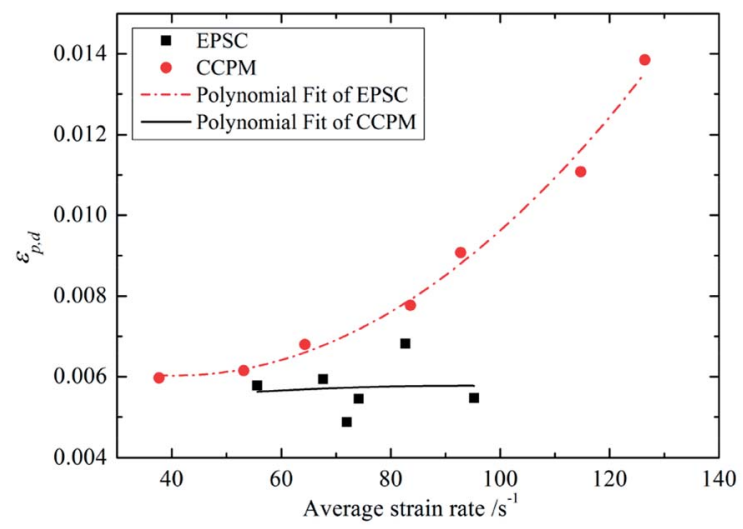

Fig. 6 The relationship between $\varepsilon_{\mathrm{p}, \mathrm{d}}$ and $\overline{\dot{\varepsilon}}$. deformation of the porous aggregate in CCPM will get larger, while the deformation of the porous aggregate in EPSC will weaken. That is because the porous aggregate in EPSC is inlaid in the stone system, the stress in the stone system will get larger with the increase of strain rate. Owing to the resistance of stone system, the stress in the porous aggregate will decrease, and the deformation will also be lowered accordingly.

Fig. 7 shows the relationship between $\varepsilon_{\mathrm{L}, \mathrm{d}}$ and average strain rate.

The Fig. 7 shows that $\varepsilon_{\mathrm{L}, \mathrm{d}}$ of lightweight porous concretes increases with strain rate, and the correlation between $\varepsilon_{\mathrm{L}, \mathrm{d}}$ and $\overline{\dot{\varepsilon}}$ can be expressed by a quadratic polynomial, as shown in formula (3):

$$
\left\{\begin{array}{l}
\varepsilon_{\mathrm{p}, \mathrm{d}(\mathrm{EPSC})}=-6.80 \times 10^{-6}(\overline{\dot{\varepsilon}})^{2}+0.00124 \overline{\dot{\varepsilon}}-0.02932 \\
\varepsilon_{\mathrm{p}, \mathrm{d}(\mathrm{CCPM})}=7.68 \times 10^{-7}(\overline{\dot{\varepsilon}})^{2}+1.77 \times 10^{-4} \overline{\dot{\varepsilon}}-4.11 \times 10^{-4}
\end{array}\right.
$$

By comparison, it shows that under low strain rate, the $\varepsilon_{\mathrm{L}, \mathrm{d}}$ of EPSC is higher than that of CCPM. But, from the analysis of correlation curve, the $\varepsilon_{\mathrm{L}, \mathrm{d}}$ of CCPM and EPSC increase with strain rate. As strain rate increases, the $\varepsilon_{\mathrm{L}, \mathrm{d}}$ of CCPM increases faster and faster while that of EPSC increases slower and slower. So it can be concluded that under high strain rate, the $\varepsilon_{\mathrm{L}, \mathrm{d}}$ of CCPM is higher than that of EPSC. And the higher the strain rate is, the more obvious this trend becomes. At present, there are few studies reporting the ultimate strain performance of porous concrete. Therefore, the results concerning about the ultimate strain performance is worthy addition to the dynamic characteristics of porous concrete.

Overall, the deformation characteristic of CCPM is better than that of EPSC. Moreover, this phenomenon becomes more obvious as the strain rate increases.

\subsection{Impact toughness}

Impact toughness is not only related to the strength of the material, but also depends on the deformation at the moment when the material breaks. It can be expressed by the area enclosed by the stress-strain curve and axial strain. ${ }^{23}$ The impact toughness of lightweight porous concrete can be



Fig. 7 The relationship between $\varepsilon_{\mathrm{L}, \mathrm{d}}$ and $\overline{\dot{\varepsilon}}$. 
identified as IT. Fig. 8 shows the relationship between IT and average strain rate.

The Fig. 8 shows that the impact toughness of lightweight porous concretes increase with strain rate, and the correlation between the IT and $\overline{\dot{\varepsilon}}$ can be expressed by an exponential function, as shown in formula (4):

$$
\left\{\begin{array}{l}
\mathrm{IT}_{(\mathrm{EPSC})}=1.324 \times 10^{-4} \mathrm{e}^{\bar{\varepsilon} / 14.50}+0.153 \\
\mathrm{IT}_{(\mathrm{CCPM})}=-0.939 \mathrm{e}^{-\overline{\dot{\varepsilon}_{\mathrm{i}}}} / 60.38+0.635
\end{array}\right.
$$

By comparison, the IT of CCPM under different strain rates is much higher than that of EPSC, and as strain rate increases, the gap between IT of CCPM and EPSC increases first and then decreases. When the average strain rate is $82 \mathrm{~s}^{-1}$, the gap reaches a maximum.

Comprehensive analysis shows that the impact toughness of CCPM is better than that of EPSC. It can also be concluded through the analysis of strength and deformation properties.

\subsection{Energy absorption properties}

$W_{\mathrm{i}}(t), W_{\mathrm{r}}(t), W_{\mathrm{t}}(t)$ are respectively defined as incident wave energy, reflected wave energy and transmitted wave energy. The expressions are shown as below:

$$
\left.\begin{array}{l}
W_{\mathrm{i}}(t)=\operatorname{EAc} \int_{0}^{t} \varepsilon_{\mathrm{i}}^{2}(t) \\
W_{\mathrm{r}}(t)=\operatorname{EAc} \int_{0}^{t} \varepsilon_{\mathrm{r}}^{2}(t) \\
W_{\mathrm{t}}(t)=\operatorname{EAc} \int_{0}^{t} \varepsilon_{\mathrm{t}}^{2}(t)
\end{array}\right\}
$$

The average incident energy change rate $\bar{W}_{\mathrm{i}}{ }^{22}$ is defined as in formula (6):

$$
\bar{W}_{\mathrm{i}}=\frac{W_{\mathrm{imax}}}{T}
$$

where $T$ is the total duration time of incident wave.

Assuming energy loss on interface between specimen and incident bar or transmitted bar is neglected, according to the

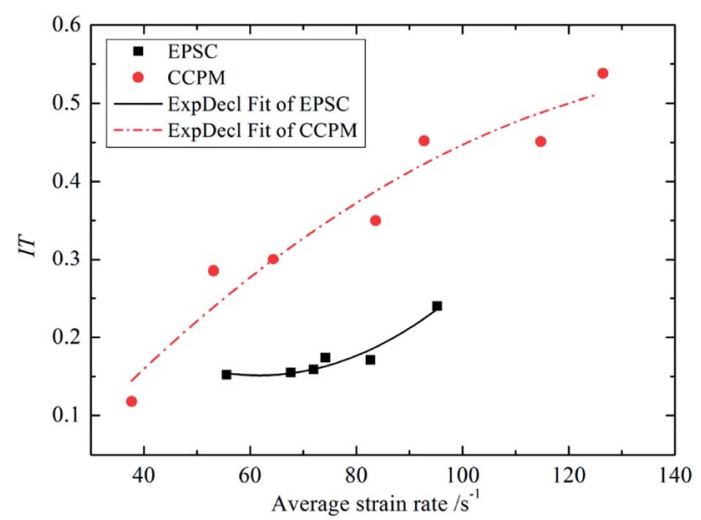

Fig. 8 The relationship between IT and $\bar{\varepsilon}$. conservation of energy; the energy absorbed by the broken specimen can be expressed as follows:

$$
W_{\mathrm{s}}(t)=W_{\mathrm{i}}(t)-W_{\mathrm{r}}(t)-W_{\mathrm{t}}(t)
$$

The energy absorption at the moment that specimen gets completely destroyed can be defined as the total energy absorption of specimen $W_{\text {smax }}$.

Fig. 9 shows the relationship between the energy absorption $W_{\text {smax }}$ and the average incident energy change rate.

According to the analysis of the Fig. 9, the relation between the $W_{\text {smax }}$ of lightweight porous concrete and $\bar{W}_{\mathrm{i}}$ is consistent with the change law between IT and $\bar{W}_{\mathrm{i}}$. That's to say, $W_{\text {smax }}$ increases with $\bar{W}_{\mathrm{i}}$, and the relationship between $W_{\text {smax }}$ and $\bar{W}_{\mathrm{i}}$ can be expressed by an exponential function, as shown in formula (8).

$$
\left\{\begin{array}{l}
W_{\text {smax }(\mathrm{EPSC})}=2.21 \times \mathrm{e}^{\bar{W}_{\mathrm{i}} / 0.924}+44.83 \\
W_{\mathrm{smax}(\mathrm{CCPM})}=-192.32 \times \mathrm{e}^{\bar{W}_{\mathrm{i}} / 0.880}+177.39
\end{array}\right.
$$

By comparison, the energy absorption of CCPM are much higher than that of EPSC under the conditions of every incident energy change rate, that's especially prominent in high strain rate. That is because the deformation characteristic of CCPM is better than that of EPSC, especially in high strain rate. Thus it can be concluded that the energy absorption characteristic of CCPM is better than that of EPSC.

\subsection{Application and mechanism analysis}

Researches $^{\mathbf{3 , 2 4 , 2 5}}$ at home and abroad show that EPSC has excellent mechanical properties. But from the analysis above, in terms of strength, deformation, impact toughness and energy characteristics, CCPM is more excellent than EPSC, and this advantage is more obvious in high strain rate. In addition, the density of CCPM is lower than that of EPSC. Therefore, CCPM has a broader application prospect in civil defense engineering than EPSC. It's necessary to continue to develop the study on CCPM, which has important theoretical and practical value.

The excellent properties of lightweight porous concrete are macro performance of mechanical properties, which is closely

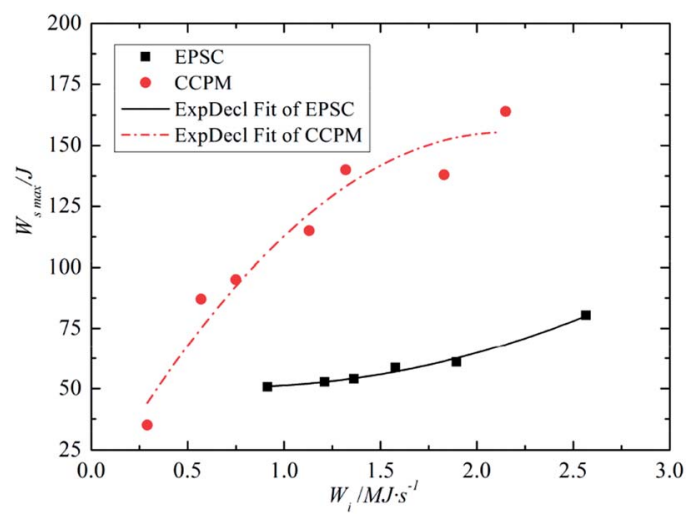

Fig. 9 The relationship between $W_{\text {smax }}$ and $W_{\mathrm{i}}$. 
connected with microstructure. Owing to the addition of EPS or porous ceramsite and alumina hollow ball, the internal part of lightweight porous concrete is full of holes, and all the internal holes are combined into the hole structure. All of the mechanical properties of lightweight porous concrete, therefore, are the combined characteristics of substrate material and hole structure. When subjected to impact loading, hole structure collapses and closes, then lightweight porous concrete can have a long trip under constant stress, and absorb a lot of energy, which can also be derived from the analysis of the stress strain curve.

Although EPSC and CCPM are lightweight porous concrete, the mechanical properties of CCPM are better than those of EPSC, which has to give the credit to the uniqueness of CCPM's inner hole structure. The holes of CCPM include tiny holes within ceramsite and the larger hollows within alumina hollow balls, and these holes have the distribution in different particle size range. However the holes of EPSC mainly include EPS particles, so the particle size is relatively single, moreover, holes of CCPM are more than those of EPSC; Compared to EPSC, the hole structures of CCPM collapse hierarchically under the loading, and the compressed space is larger, so the mechanical properties of CCPM are better than those of EPSC.

\section{Conclusions}

The dynamic mechanical experiments of the two types of lightweight porous concrete (EPSC and CCPM) have been carried out with $\Phi 100 \mathrm{~mm}$ SHPB device improved by wave shaping technology. The dynamic properties of lightweight porous concretes, including strength property, deformation property, energy absorption properties and impact toughness, have been analyzed contrastively, and its application prospects have also been discussed.

The two types of lightweight porous concrete are strain rate sensitive materials. The mechanical properties, including strength, peak strain, ultimate strain and impact toughness, are change with the increase of strain rate. Under impact loading, the total energy absorption of lightweight porous concrete increases with incident energy change rate, and the relationship between them is expressed by an exponential function. Compared with EPSC, CCPM is more excellent in terms of strength, deformation, impact toughness and energy, and the advantage is more outstanding under high strain rate.

In view of the fact that the mechanical properties of CCPM are better than those of EPSC, CCPM has a broader application prospect in civil defense engineering than EPSC.

\section{Conflicts of interest}

There are no conflicts to declare.

\section{Acknowledgements}

Projects of National Natural Science Foundation of China (51208507, 51378497).

\section{References}

1 M. J. Silva and L. J. Gibson, The effects of non-periodic microstructure and defects on the compressive strength of two-dimensional cellular solids, Int. J. Mech. Sci., 1997, 39(5), 549-563.

2 L. L. Wang, Progress in Studies on Dynamic Response of Structures and Materials under Explosive/Impact Loading, Combust., Explos. Shock Waves, 2001, 2889-2900.

3 B. Chen and J. Liu, Properties of lightweight expanded polystyrene concrete reinforced with steel fiber, Cem. Concr. Res., 2004, 34(7), 1259-1263.

4 P. Y. González and M. del Río Merino. Mechanical Performance of Traditional Lightweight Concretes from the Canary Islands, Construction and Building Research, Springer, Netherlands, 2014, pp. 547-553.

5 F. Lo Monte, P. Bamonte and P. G. Gambarova, Physical and mechanical properties of heat-damaged structural concrete containing expanded polystyrene synthesized particles, Fire Mater., 2014, 58-71.

6 X. Luo, J. Xu, E. Bai, et al., Mechanical properties of ceramics-cement based porous material under impact loading, Mater. Des., 2014, 55, 778-784.

7 A. S. Lim, Q. An, T. W. Chou, et al., Mechanical and electrical response of carbon nanotube-based fabric composites to Hopkinson bar loading, Compos. Sci. Technol., 2011, 71(5), 616-621.

8 O. S. Lee and J. S. Park, Dynamic deformation behavior of bovine femur using SHPB, J. Mech. Sci. Technol., 2011, 25(9), 2211-2215.

$9 \mathrm{H}$. Kolsky, An investigation of the mechanical properties of materials at very high rates of loading, Proc. Phys. Soc., London, Sect. B, 1949, 62(11), 676.

10 D. J. Frew, M. J Forrestal and W. Chen, Pulse Shaping techniques for testing brittle materials with a split Hopkinson pressure bar, Exp. Mech., 2002, 42(1), 93-106.

11 O. S. Lee, S. H Kim and Y. H Han, Thickness effect of pulse shaper on dynamic stress equilibrium and dynamic deformation behavior in the polycarbonate using SHPB technique, Exp. Mech., 2006, 21(1), 51-60.

12 L. Xin, X. Jinyu, L. Weimin and Z. Jun., Numerical simulation and spectral Analysis of dispersion effect of stress pulse in SHPB tests, Exp. Mech., 2010, 25(4), 451-456.

$13 \mathrm{X}$. jinyu, L. weimin, et al., The research of impacting mechanics property of geopolymer concrete, J. Sound Vib., 2009, 28(1), 46-51.

14 C. A. Ross, J. W. Tedesco and S. T. Kuennen, Effects of strainrate on concrete strength, ACI Mater. J., 1995, 92(1), 37-47.

15 C. A. Ross, D. M. Jerome, J. W. Tedesco and M. L. Hughes, Moisture and strain rate effects on concrete strength, ACI Mater. J., 1996, 93(3), 293-300.

16 J. W. Tedesco, C. A. Ross and S. T. Kuennen, Experimental and numerical analysis of high strain rate splitting tensile tests, ACI Mater. J., 1993, 90(2), 162-169.

17 W. M. Li and J. Y Xu, Impact characterization of basalt fiber reinforced geopolymeric concrete using a 100-mm-diameter 
split Hopkinson pressure bar, J. Mater. Sci. Eng. A, 2009, 513514, 145-153.

18 G. Gary and P. Bailly, Behaviour of quasi-brittle material at high strain rate. Experiment and modeling, Eur. J. Mech. ASolid, 1998, 17(3), 403-420.

19 F. Ragueneau and F. Gatuingt, Inelastic behavior modelling of concrete in low and high strain rate dynamics, Comput. Struct., 2003, 81(12), 1287-1299.

$20 \mathrm{~J}$. W. Tedesco and C. A. Ross, Strain-rate-dependent constitutive equations for concrete, J. Pressure Vessel Technol., 1998, 120(4), 398-405.

21 W. H. Dilger, R. Koch and R. Kowalczyk, Ductility of plain and confined concrete under different strain rates, $A C I$ Journal Proceedings. ACI, 1984, 81(1), 73-81.
22 W. Xutao, D. Renqiang, et al., Energy dissipation analysis on dynamic splitting-tensile test of steel fiber reinforced concrete, Chin. J. Appl. Mech., 2009, 26(1), 151-154.

23 Z. Liu, Y. Luo, H. Bai, et al., Remarkably enhanced impact toughness and heat resistance of poly(L-lactide)/ thermoplastic polyurethane blends by constructing stereocomplex crystallites in the matrix, ACS Sustainable Chem. Eng., 2016, 4(1), 111-120.

24 B. Chen and C. Fang, Mechanical properties of EPS lightweight concrete, Proceedings of the ICE-Construction Materials, 2011, 164(4), pp. 173-180.

25 C. M. Cheng, D. G. Su, J. He, et al., Compressive Strength of Organic Lightweight Aggregate Concrete, Adv. Mater. Res., 2012, 374, 1531-1536. 